\title{
Therapy-Related Leukemia
}

National Cancer Institute

\section{Source}

National Cancer Institute. Therapy-Related Leukemia. NCI Thesaurus. Code C80683.

A leukemia arising as a result of the mutagenic effect of chemotherapy ag ents that are used for the treatment of a malignant tumor or exposure to ionizing radiation. 